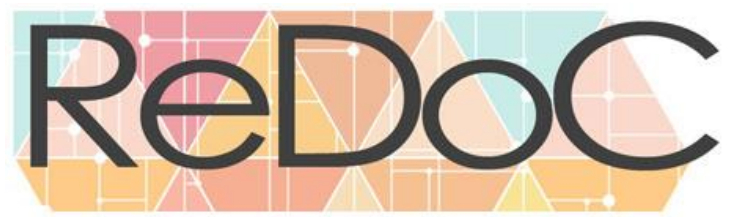

Revista Docência e Cibercultura

\title{
Novas práticas sociais no campo da educação museal: a cultura digital e a sociabilidade em rede
}

\author{
New social practices in the field of museum education: digital culture and network \\ sociability
}

\author{
Nuevas prácticas sociales en el campo de la educación museística: cultura digital y \\ sociabilidad de redes
}

Luciana Conrado Martins ${ }^{2}$ Dalton Lopes Martins ${ }^{3}$

\section{RESUMO}

A educação museal tem se constituído como um campo de estudos cujos interesses convergem, em grande medida, para a delimitação de sua especificidade. Compreender quais atores, práticas, processos e políticas que atuam nesse campo, bem como seus impactos percebidos tanto na instituição museal quanto na sociedade, são temas de estudo que contribuem para delimitar seu escopo e solucionar questões advindas da prática educacional museal. O uso das tecnologias digitais e a criação de uma infraestrutura informacional em rede nos museus nacionais tem surgido como um tema importante de investigação nos últimos anos, seja pela perspectiva de novas formas de socializar os acervos e ampliar seu potencial de apropriação simbólica, seja por novas práticas de gerir e organizar os museus para suas atividades fins. Entretanto, poucas são as reflexões que se debruçam sobre seus usos e impactos na educação museal, sobretudo aquelas que se propõem a entender seus efeitos e possibilidades para além do simples uso direto de determinadas técnicas e tecnologias. Que novas possibilidades de exercício do educar em museus essas práticas podem trazer? De que maneiras essas possibilidades podem dialogar com a gestão e a socialização dos acervos? Como pensar a formação do museólogo a partir desse cenário? De que formas novos usos da informação podem potencializar a prática da museologia? Este artigo pretende debater, a partir de uma reflexão teórica, como os educadores museais podem, frente às perspectivas apontadas pelos novos cenários informacionais, estabelecer processos de sociabilidade em rede por meio das novas práticas sociais vivenciadas pela cultura digital.

\section{Submetido em: 26/08/2019 - Aceito em: 29/08/2019 - Publicado em: 31/08/2019.}

\footnotetext{
${ }^{2}$ Historiadora, com especialização em Museologia e doutorado em Educação, atuo desde da graduação na área de museus e patrimônio, com especial ênfase na educação e na difusão de acervos. Desde 2016 desenvolve projetos e pesquisas sobre tecnologias digitais para museus e instituições culturais, trabalhando a partir da potencialidade do uso dessas tecnologias para a organização e a difusão dos acervos. Tem atuação em diferentes instituições, como Museu de São Carlos, a Expomus e o Instituto Butantan. Desde 2009 é sócia da Percebe (www.percebeeduca.com.br), empresa voltada para a consultoria a museus e instituições culturais. É coordenadora de estratégia institucional e pesquisa do projeto Tainacan, onde atua como responsável pela pesquisa de maturidade tecnológica dos museus do Ibram, e na implantação do Tainacan nos museus.

${ }^{3}$ Professor no curso de Biblioteconomia e do PPGCINF da Faculdade de Ciência da Informação na Universidade de Brasília (UnB) e no PPGCOM (Mestrado) da Faculdade de Informação e Comunicação da Universidade Federal de Goiás. Graduação em Engenharia Elétrica e mestrado em Engenharia da Computação pela UNICAMP e doutor em Ciências da Informação pela ECA-USP. Tem experiências nas áreas de inclusão e cultura digital, análise de redes sociais, estudos métricos, organização e representação da informação e aprendizagem de máquina. Têm trabalhado com acervos e repositórios digitais, sobretudo na área da cultura, dados abertos ligados e websemântica, com especial interesse em estratégias de interoperabilidade de sistemas de informação. Coordena o projeto de pesquisa Tainacan - software livre para a construção social de repositórios digitais.
} 


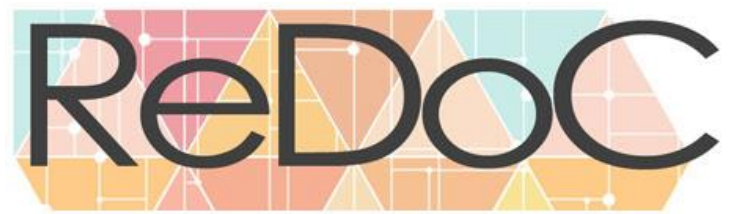

\section{Revista Docência e Cibercultura}

PALAVRAS-CHAVE: educação museal; cultura digital; sociabilidade em rede.

\section{ABSTRACT}

Museum education has been constituted as a field of studies whose interests converge, largely, towards the delimitation of its specificity. Understanding which actors, practices, processes and policies that work in this field, as well as their perceived impacts both in the museum institution and in society, are topics of study that contribute to delimit its scope and solve issues arising from the educational museum practice. The use of digital technologies and the creation of a networked information infrastructure in national museums has emerged as an important research topic in recent years, either through the perspective of new ways of socializing the collections and increasing their potential for symbolic appropriation, practices of managing and organizing museums for their activities purposes. However, there are few reflections about its uses and impacts on museum education, especially those that aim to understand its effects and possibilities beyond the simple direct use of certain techniques and technologies. What new possibilities for the practice of museum education can these practices bring? In what ways can these possibilities interact with the management and socialization of the collections? How to think about the formation of the museologist from this scenario? In what ways new uses of information can enhance the practice of museology? This article intends to discuss, from a theoretical reflection, how the museum educators can, in front of the perspectives pointed out by the new informational scenarios, to establish processes of sociability in network through the new social practices experienced by the digital culture.

KEYWORDS: museum education; digital culture; network sociability.

\section{RESUMEN}

La educación museística se ha constituido como un campo de estudio cuyos intereses convergen, en gran medida, a la delimitación de su especificidad. Comprender qué actores, prácticas, procesos y políticas que actúan en este campo, así como sus impactos percibidos tanto en la institución museística como en la sociedad, son temas de estudio que contribuyen a delimitar su alcance y resolver problemas derivados de la práctica educativa de los museos. El uso de tecnologías digitales y la creación de una infraestructura de información en red en los museos nacionales se ha convertido en un tema de investigación importante en los últimos años, ya sea desde la perspectiva de nuevas formas de socializar colecciones y expandir su potencial de apropiación simbólica, o de nuevas. prácticas de gestión y organización de museos para sus fines actividades. Sin embargo, hay pocas reflexiones sobre sus usos e impactos en la educación del museo, especialmente aquellos que proponen comprender sus efectos y posibilidades más allá del simple uso directo de ciertas técnicas y tecnologías. ¿Qué nuevas posibilidades para practicar la educación museística pueden aportar estas prácticas? ¿De qué manera estas posibilidades pueden dialogar con la gestión y socialización de las colecciones? ¿Cómo pensar en la formación del museólogo a partir de este escenario? ¿De qué maneras pueden los nuevos usos de la información mejorar la práctica de la museología? Este artículo pretende discutir, desde una reflexión teórica, cómo los educadores museales pueden, frente a las perspectivas señaladas por los nuevos escenarios informativos, establecer procesos de sociabilidad en red a través de las nuevas prácticas sociales vividas por la cultura digital.

PALABRAS CLAVE: educación museística; cultura digital; sociabilidad en la red.

\section{INTRODUÇÃO}

A especificidade da educação museal tem se constituído como um importante tema de investigação entre os pesquisadores e profissionais de museus na última década. Balizar as características dessa modalidade educacional faz parte de um esforço de constituição do próprio

\begin{tabular}{l|l|l|l|l|l|r} 
(C) Redoc & Rio de Janeiro & v. 3 & n.2 & p. 200 & Maio/Agosto 2019 & ISSN 2594-9004
\end{tabular}




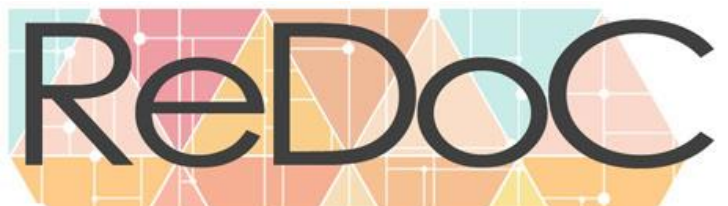

\section{Revista Docência e Cibercultura}

campo da educação museal e de seu reconhecimento como um objeto de investigação legítimo. Sabe-se que, historicamente, os museus tinham suas missões institucionais ligadas a um sem número de atividades relacionadas à preservação das coleções sob sua guarda. Coletar, catalogar, estudar e manter objetos de interesse, vindos do mundo natural e do mundo cultural, eram algumas das atribuições que classicamente estavam sob a responsabilidade das instituições museais. A essas funções foram se agregando, e adquirindo cada vez maior importância, a comunicação e a educação. Essa mudança, ainda em andamento nos dias atuais, teve início na segunda metade do século XX e transferiu a principal vertente de atuação dos museus, historicamente voltada para a guarda e o estudo de seus acervos, para o público.

O movimento que deu impulso a essas transformações é conhecido no interior na comunidade museológica como movimento da Nova Museologia e teve como foco o questionamento acerca do papel e das responsabilidades das instituições culturais frente às transformações e problemas presentes na sociedade. Esse movimento representou novos paradigmas de atuação profissional, responsáveis pela potencialização tanto do acesso de um público mais diversificado aos museus, quanto do surgimento de novos modelos e iniciativas institucionais. Como consequência, na balança da cadeia operatória museológica (BRUNO, 1996a, 1996b; 2004), ou seja, das ações que comumente compõem o universo de práticas preservacionistas de um museu, as exposições, as ações educativas e demais atividades voltadas para o público, ganharam um peso e uma relevância cada vez maiores (Hooper-Greenhill, 1994).

Apesar dessa mudança não acontecer sem tensões no próprio universo museal, a educação tem assumido uma relevância cada vez maior, seja como tema de pesquisa e produção de conhecimento, seja como prática no interior das instituições e processos museológicos. No Brasil, esse crescimento também está refletido no surgimento e fortalecimento das redes de educadores de museus (REM) e, principalmente, na construção da Política Nacional de Educação Museal (PNEM) (IBRAM, 2017). O potencial da educação museal na extroversão e apropriação, pelos diferentes públicos, do patrimônio salvaguardado pelos museus é amplamente comprovado pela literatura pertinente (BIZERRA, 2009, ROBERTS, 1997, CAZZELI et al., 2003; entre outros). Parte da importância assumida pela educação museal nas últimas décadas está relacionada, inclusive, com a realização de estudos de público que corroboram a importância dessas práticas na construção de um museu mais democrático, plural e acessível a todos os tipos de visitantes (ALMEIDA et al., 2003).

Essa perspectiva de atuação se coaduna com as possibilidades trazidas pelo uso das tecnologias digitais nos museus. De acordo com Vessuri, as tecnologias permitem que os públicos tenham novas experiências nos museus, além de ampliarem as formas de interação a partir de experiências já conhecidas. De acordo ainda com esse autor, "as mudanças tecnológicas também tiveram impacto nas expectativas dos visitantes acerca de como receberão e 


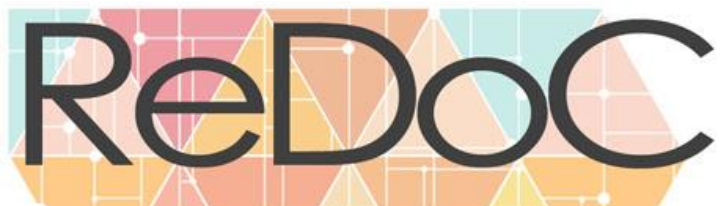

\section{Revista Docência e Cibercultura}

contribuirão com informações no contexto do museu." (Vessuri, 2017, p. 51, tradução nossa). Tornar o patrimônio museal mais acessível a um número maior de pessoas, democratizando o acesso às instituições museais é, dessa forma, uma perspectiva que se coloca tanto para o fazer educacional museal quanto para o uso das tecnologias digitais nos museus. Vale destacar que esse é o elemento fundamental a se considerar, pois o foco no público permite levar a novas reflexões sobre as práticas de socialização no século XXI e criar uma importante chave de leitura dos dispositivos digitais como meio para a produção de novas redes sociais de produção e consumo de informações museais, o que nos levará a questionar de que maneira esses novos usos incidem nas práticas museais. Novas camadas de socialização dos museus com o público passam a estar disponíveis para o exercício do fazer museal. É importante ressaltar, que essas novas possibilidades não se opõem, em nenhuma instância, à promoção do acesso presencial dos públicos aos museus. Pelo contrário, é factível considerar que as práticas sociais estabelecidas pelas tecnologias digitais facilitem e promovam esse acesso. Estudos demonstram que o número de visitas locais a um museu pode crescer significativamente quando seus acervos estão disponíveis em rede (NAVARRETE e BOROWIECK, 2015).

Partindo dessa premissa, o presente artigo busca refletir acerca dos usos e impactos das tecnologias digitais na educação museal, sobretudo aquelas que se propõem a entender seus efeitos e possibilidades para além do simples uso direto de determinadas técnicas e tecnologias. Que novas possibilidades de exercício do educar em museus essas práticas podem trazer? De que maneiras essas possibilidades podem dialogar com a gestão e a socialização dos acervos? Como pensar redes informacionais de apoio a essas novas práticas de socialização? Como pensar a formação do museólogo e, mais precisamente, do educador museal, a partir desse cenário? Este artigo pretende debater como os setores educativos museais podem, a partir das perspectivas apontadas pelo uso das tecnologias digitais, estabelecer processos de sociabilidade em rede por meio das novas práticas sociais vivenciadas pela cultura digital. Propõe-se uma reflexão de natureza qualitativa a partir da especificidade da educação museal, compreendida como uma modalidade educacional que acontece nos museus e nos processos museais, e que tem características próprias relativas aos programas, projetos e ações educativas museais, além de constituir um campo de produção de conhecimento autônomo (COSTA et al., 2018; AUTOR, 2015). Para isso, foi realizada ampla pesquisa bibliográfica, a partir de autores referenciais da área, estabelecendo um debate propositivo sobre as novas formas de fazer a educação museal no contexto da cultura digital.

\section{CARACTERÍSTICAS DA EDUCAÇÃO MUSEAL}




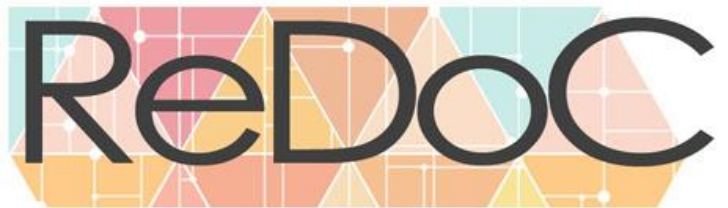

\title{
Revista Docência e Cibercultura
}

A educação museal e suas características vêm sendo debatidas por autores da área que se preocupam em compreender como funciona e se constitui essa modalidade educacional. Costa et al. (2017, p. 73), definem na publicação "Caderno da Política Nacional de Educação Museal" que,

\begin{abstract}
A Educação Museal envolve uma série de aspectos singulares que incluem: os conteúdos e as metodologias próprios; a aprendizagem; a experimentação; a promoção de estímulos e de motivação intrínseca a partir do contato direto com o patrimônio musealizado, o reconhecimento e o acolhimento dos diferentes sentidos produzidos pelos variados públicos visitantes e das maneiras de ser e estar no museu; a produção, a difusão e o compartilhamento de conhecimentos específicos relacionados aos diferentes acervos e processos museais; o estímulo à apropriação da cultura produzida historicamente, ao sentimento de pertencimento e ao senso de preservação e criação da memória individual e coletiva (COSTA et al., 2017, p.73).
\end{abstract}

Entre os vários aspectos apontados pelos autores, se destaca como singularidade da educação museal o contato com o patrimônio museal, o ser e estar nos museus e a difusão dos conhecimentos específicos relacionados aos acervos dessas instituições. Mais do que transmitir conhecimentos, a educação museal traz uma perspectiva dialógica que tem no público, visitante e potencial, seu eixo estruturador. A esse respeito, Aidar e AUTOR (2018, p. 168), ao discutir como o conceito de educação museal é compreendido pelos profissionais desse campo na América Latina, afirmam que:

Os públicos aparecem de forma central na fala desses sujeitos, tanto como catalisadores, quanto como alvo das ações desenvolvidas pelas instituições. Essa noção ampliada do papel da instituição museal e da potência da relação com os diferentes públicos aparece nas respostas [dos profissionais dos museus] sobre o significado da ação educativa, que desvincula a educação em museus da educação escolar e seus públicos exclusivamente (AIDAR, AUTOR; 2018, p.168).

Nesse mesmo sentido, Autor (2018), ao discutir a possibilidade da existência de um currículo da educação museal, aponta que são as características, objetivos e necessidades dos visitantes um dos principais fatores que estruturam as ações educativas museais.

Fato é que a educação museal vem se constituindo historicamente como um dos processos museais que favorecem a promoção do diálogo dos museus com a sociedade. A perspectiva de atuação dos educadores museais foi se transformando ao longo de sua existência e, na atualidade, os setores educativos são responsáveis por um sem número de atividades voltadas à compreensão e ao diálogo com todo o tipo de público. Roberts (1997, p. 2, tradução nossa), ao debater a crescente importância dos setores educativos nos museus atuais ressalta que as funções assumidas pelos educadores contemporâneos incluem mais do que educar.

Eles estão envolvidos em toda uma série de atividades que se relacionam amplamente 
com a educação e os públicos: por exemplo, desenvolvimento de programas e exposições, viagens de campo escolares, formação de professores, educação continuada, extensão comunitária, administração de voluntários, estudos de público, e arrecadação de fundos (ROBERTS, 1997, p.2).

Essas possibilidades de atuação foram sendo consolidadas a partir de meados do século XX, quando a educação museal foi, paulatinamente, conquistando um espaço mais ampliado frente às demais funções museais (VALENTE, 2003). Nesse sentido são importantes as discussões que, no interior da área museal, forjaram essa relevância. Dos encontros sobre a educação em museus, patrocinados pela Unesco, às discussões sob a égide da Nova Museologia, a partir da década de 1970, a educação, por meio da "utilidade social" dos museus se tornou um dos novos pilares da atuação dessas instituições ${ }^{4}$. As forças sociais e intelectuais que forjaram o papel da importância social dos museus na atualidade trouxeram para o centro do palco as práticas educacionais dessas instituições. Essas práticas, que tiveram suas origens fortemente apoiadas na recepção aos grupos escolares foram paulatinamente se diversificando e, com o apoio de múltiplos sujeitos - principalmente os educadores museais - foram se estruturando em setores educacionais específicos dentro dessas instituições. São esses setores os atuais responsáveis pela concepção e prática do que se denomina na contemporaneidade de educação museal.

A constituição das práticas educacionais, nesse sentido, se apoia na percepção dos museus como espaços de socialização do conhecimento e democratização do acesso ao patrimônio cultural da humanidade. O entendimento do museu como espaço de educação, tendo no público o eixo central, vincula a relevância social contemporânea dessas instituições a sua capacidade de educar seus públicos (HOOPER-GREENHILL, 1994) e concorre diretamente com a visão dos museus como espaços prioritariamente dedicados à guarda, à pesquisa e à proteção de acervos.

A cultura digital vem ao encontro a esse contexto, propondo transformações na forma como os públicos podem se relacionar com os museus. Nesse sentido, cabe refletir acerca de quais são os potenciais impactos trazidos pelos usos das tecnologias na missão educacional dos museus. Existe uma possibilidade de atuação educacional no espaço social digital? Se sim, quais são elas?

\section{A CULTURA DIGITAL: ELEMENTOS PARA PENSAR A EDUCAÇÃO MUSEAL}

\footnotetext{
4 Compreende-se como marco fundador da Nova Museologia a Mesa Redonda de Santiago do Chile, em 1972 (SANTOS, 2008; BRUNO, 2010).
} 


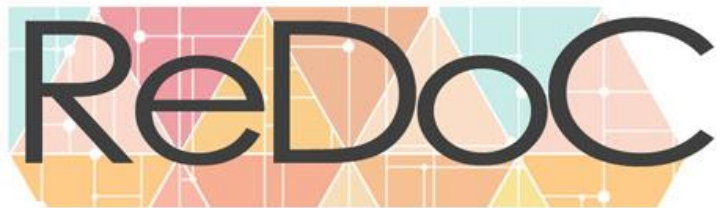

\title{
Revista Docência e Cibercultura
}

Mais do que definir cultura digital, torna-se fundamental para a presente discussão refletir sobre como observar os efeitos dessa cultura, e de que maneira isso pode contribuir para o campo da pesquisa e prática na educação museal. A questão da socialização do simbólico se mostra como ponto de observação do fenômeno:

\begin{abstract}
Entendendo aqui cultura como conceito meio, operador de aberturas de significado que permite observar as práticas sociais em seu contínuo movimento do conviver em torno das diferentes formas possíveis de socialização do simbólico, entende-se "cultura digital" como um conjunto de práticas sociais que acontecem de forma singular no espaço social digital. É importante destacar a ideia de singularidade para que se possa falar de cultura digital, visto que há práticas que só podem se dar nesse espaço social e que terminam por ser inerentes às condições desse espaço (possibilidades e restrições), quer sejam tais práticas técnicas, em relação ao meio no qual se dão, ou sociais, em relação ao tipo de interação por meio do qual se socializa (AUTOR, 2018, p.54).
\end{abstract}

Daí se apreende um aspecto que se aplica diretamente ao contexto da educação museal, qual seja, as condições técnicas de novas formas de socialização do simbólico permitindo o exercício de novos tipos de interação que merecem aqui serem analisados e contextualizados. A mobilidade da informação e a crescente capacidade de gerir essa mobilidade, característica das diferentes práticas da cultura digital, abre um sem número de possibilidades de socialização dessa informação que podem ter aplicações diretas ao campo da educação museal. Varine (2013, pag. 19), falando sobre o conceito de subsidiariedade, parece dialogar diretamente com essa possibilidade quando explicita que a "gestão do patrimônio deve ser feita o mais próximo possível dos criadores e dos detentores desse patrimônio (...). O papel das instituições especializadas é sensibilizar, facilitar, educar, pôr em contato, mediatizar, gerir pela margem em função do interesse geral."

A condição técnica dessa mobilidade da informação que amplia as possibilidades sociais de colocar em contato se fundamenta no conceito do hipertexto. Este fenômeno que vai se constituir ao longo do século XXI como um poder social materializado na visão de uma sociedade organizada em rede, terá grandes implicações na reorganização das formas tradicionais de produção do conhecimento de praticamente todas as áreas do saber. Segundo Barbier:

[...] trata-se de estruturar os dados não mais de maneira linear e hierarquizada (como num texto impresso), mas sob a forma de "tela" oferecendo a possibilidade de "clicar" numa palavra ou grupo de palavras para acessar a novas informações, elas mesmas multimídias, portanto recorrendo à imagem e ao som. A realidade do hipertexto mobilizou todas as práticas ligadas à construção e à disponibilização do saber (BARBIER, 2018, p.364).

Ao organizar a informação pela racionalidade do hipertexto passa-se a exercer maior 


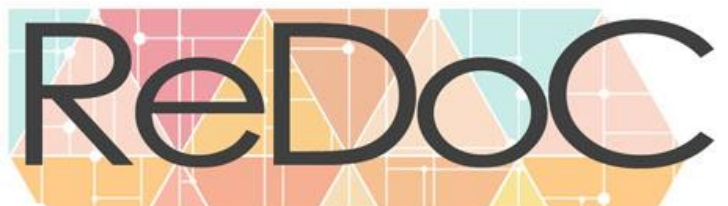

\section{Revista Docência e Cibercultura}

possibilidade de fragmentá-la em módulos que podem ser combinados e recombinados de diferentes maneiras possíveis, distribuídos em partes ou conectados a visões de articulação de um todo, recortados em pedaços, conectados com outras partes, recombinados com outros módulos de informação e estabelecendo inúmeras redes informacionais de conexão entre fragmentos de informação em múltiplas mídias. É dessa possibilidade de criar redes de informação, a partir do ganho substancial de mobilidade que o hipertexto fornece, permitindo pensar novas dinâmicas de relacionamento social em torno dessas redes informacionais, que se instaura um conjunto de novas práticas sociais.

É fato que essa mobilidade não traz apenas maior possibilidade de circulação da informação em rede, mas também e, com enorme potencial para se pensar em processos educacionais, possibilidades da produção de novos conhecimentos ao se conectar e recombinar pedaços de informação que nunca foram combinados antes, gerando efeitos potencialmente criativos ao se deparar com novas formas de observação, novos pontos de vista e novas formas de compreensão dos fenômenos. Burke se refere a essa possibilidade como uma forma de bricolagem:

Em vez de uma transmissão em sentido único, mais vale pensar na circulação de conhecimentos em termos de uma "negociação" de informações e ideias ou de um diálogo (por vezes, um diálogo de surdos). Uma consequência importante dessa visão é que inevitavelmente se embaça a diferença entre produzir novos conhecimentos e transmitir velhos conhecimentos. Muitas vezes a inovação é uma espécie de bricolagem, uma reconfiguração de conhecimentos que resulta de um contato entre culturas diferentes (BURKE, 2012, p.113).

Mas, cabe aqui perguntar, por que seria tão relevante para se pensar a educação museal a questão de quão flexível, móvel e passível de recombinação são as informações museais, sobretudo aquelas referentes ao seu acervo e que constituem o patrimônio da instituição? A educação museal é exercida, conforme ressalta a PNEM, a partir de variadas estratégias e processos de trabalho que se valem do contato com o patrimônio musealizado como um de seus elementos. Torna-se aqui evidente impulsionador de tal política, portanto, a possibilidade do exercício de novas práticas sociais que tenham por objetivo estabelecer contato com o patrimônio musealizado com finalidades educacionais.

Explicitando de outra maneira, o que se evidencia aqui é a possibilidade de se utilizar de uma maior flexibilidade de organização e estruturação da informação a respeito do patrimônio musealizado, criando novos tipos de redes informacionais que tenham como finalidade ampliar o contato entre o público e o patrimônio, gerando novas camadas de apropriação e uso social dos acervos e coleções. Ao produzir esses novos tipos de redes informacionais, falando em termos práticos, torna-se possível ampliar o potencial de circulação do patrimônio, sendo viável 
que o mesmo possa ser utilizado em ambientes de redes sociais (Facebook, Twitter, Instagram, etc.), aplicativos de mensagens instantâneas (Whatsapp, Telegram, etc.), blogs, sites na web, bancos de dados distribuídos, entre tantas outras formas sócio-técnicas de produção de redes informacionais. É fato que essa informação, uma vez disponibilizada de maneira mais flexível e trabalhada em estratégias educacionais, teria maiores condições de disputar sentidos, espaços e atuar de forma mais eficiente como forma de socialização da cultura para inúmeros usuários que hoje pouco ou nada acessam as instituições de memória fisicamente ${ }^{5}$.

Pensar na produção dessas redes informacionais é, de certa maneira, pensar na instituição como um todo, considerando, como afirma Jacob (2006) referindo-se às bibliotecas, que:

Por sua arquitetura, definição de seu público, princípios que ordenam suas coleções, pelas opções tecnológicas que determinam a acessibilidade e a materialidade dos textos, assim como pela visibilidade das escolhas intelectuais que organiza sua classificação, toda biblioteca dissimula uma concepção implícita da cultura, do saber e da memória, bem como da função que lhes cabe na sociedade de seu tempo (JACOB, 2016, p.17).

Logo, a forma de organização da informação a respeito do patrimônio musealizado, tradicionalmente pensada como a documentação e o inventário do acervo, são reflexos dessa concepção implícita da cultura, das escolhas intelectuais de categorização, dos padrões desenvolvidos institucionalmente para catalogação, dos vocabulários controlados utilizados ou não utilizados, dos tipos de informação escolhidas para se descrever e das não escolhidas e, por que não enfatizar, da própria história, cultura institucional e das possibilidades de extroversão de seu acervo. Instituições diferentes, a partir de suas próprias realidades, se organizam produzindo diferentes estratégias e formas de lidar com sua própria informação, muitas das vezes não chegando a refletir explicitamente sobre essas escolhas. Nesse ponto, a educação museal permite colocar em questão, ao se pensar a partir das racionalidades da cultura digital, todos esses aspectos, facilitando a própria instituição se olhar antropologicamente, rever escolhas, compreender e explicitar decisões tomadas tacitamente e estabelecer novos processos de trabalho que tenham por objetivo ampliar a mobilidade da informação e estabelecer redes informacionais mais eficientes, de maior proximidade e acesso com seu público em potencial. Para que isso se torne efetivo em termos de processo de trabalho para os museus, é fundamental que a instituição conheça algumas das práticas sociais da cultura digital e possa se apropriar gradativamente dessas práticas na concepção de suas estratégias educacionais.

\footnotetext{
${ }^{5}$ É importante considerar nessa discussão o fato de que apenas $27,2 \%$ dos municípios brasileiros possuem museus, segundo dados do IBGE. Disponível em: https://agenciadenoticias.ibge.gov.br/agencia-sala-deimprensa/2013-agencia-de-noticias/releases/9611-estadic-munic-cultura-em-2014-estados-emunicipios-apoiaram-a-producao-de-1-849-filmes. Acesso em 15/07/2019.
} 


\section{CARACTERIZANDO O OBJETO DIGITAL E AS PRÁTICAS DA CULTURA DIGITAL: SUGESTÕES PARA O CAMPO DA EDUCAÇÃO MUSEAL}

Antes de mencionar as possibilidades de prática da cultura digital para o campo da educação museal e se dedicar ao exercício de pensar como isso pode ser apropriado por essa área, é fundamental estabelecermos uma definição mais precisa e descrever quais são as características inerentes aos objetos digitais. É apenas pelo reconhecimento de suas especificidades que se torna possível elucidar as práticas de socialização específicas que podem ser úteis para a compreensão do tema em questão.

O primeiro elemento a se destacar é estabelecer uma diferenciação entre o conceito de "objeto digital" e a ideia, oriunda do senso comum, de que o objeto digital consiste apenas em um arquivo digital representando um conteúdo específico, armazenado em disco, copiado em um pendrive, enviado por email para alguém ou compartilhado para outra pessoa via um aplicativo de mensagem instantânea. Certamente, o arquivo é uma das dimensões a se considerar de um objeto digital, mas o que se pretende estabelecer aqui é uma outra perspectiva.

Segundo Hui (2012), um objeto digital é caracterizado por três camadas, não podendo ser resumido apenas a uma delas. Essas três camadas são denominadas objetos, dados e redes. $\mathrm{Na}$ camada objeto, o que se percebe do objeto digital é o que mais se evidencia no sentido comum, o fato de que ele consiste em objeto abstrato, como um arquivo digital e que encapsula o conteúdo, representando um objeto oriundo da natureza ou um objeto técnico construído por meio de recursos digitais, tais como a fotografia digital de uma flor ou um texto nascido digitalmente em um editor de texto. Na camada dados, se evidencia outra característica desse objeto, o fato de que ele é formado por um conjunto agrupado de dados digitais, que podem ser manipulados, extraídos, sintetizados, tais como os procedimentos técnicos de se extrair uma tabela de um texto, uma imagem de um livro ou um endereço de uma lista telefônica. O objeto digital pode ser constituído por dados que podem eles mesmos serem trabalhados e tratados separadamente, sendo reintegrados para a formação de um outro objeto digital. Já na camada rede, o que se evidencia é a possibilidade desse objeto ser descrito e representado por padrões que permitam que ele possa ser inserido em meio a outros objetos digitais e fazer parte de coleções, acervos, repositórios e redes de dados. Nessa última camada, se ressaltam os elementos e as possibilidades descritivas do objeto, como o uso de metadados e modelos conceituais para descrever suas características específicas e o uso de taxonomias para indexação de seu conteúdo. 
Em outras palavras, os objetos digitais podem ser percebidos como sendo compostos por camadas de informação que se somam e compõem recursos informacionais que os tornam flexíveis, maleáveis e passíveis de tratamento de maneiras específicas que não são possíveis a objetos analógicos. Compreender essas camadas e transformá-las em elementos possíveis de se gerenciar e utilizar de forma a atender demandas específicas de um projeto, qualquer que seja, é um dos maiores desafios de apropriação do digital como elemento de empoderamento cultural e social. É preciso, em certo sentido, dominar sua volatilidade, compreendendo suas características e os modos de administrá-las, para que os mesmos possam ser tratados como recursos a disposição dos coletivos humanos e às suas respectivas formas de entendimento e organização da informação.

Essa flexibilidade dos objetos é percebida por Kallinikos, Aaltonem e Marton (2010) por um conjunto de 4 atributos que caracterizam as especificidades dos objetos digitais. Eles são constituídos pela possibilidade de editabilidade, que consiste na possibilidade de alterar os objetos, suprimir elementos, incluir novas partes, modificar as já existentes. São interativos, característica que evidencia qualidades de diferentes modos de manipulação dos objetos, tais como, aumentar o zoom de uma imagem para observá-la em detalhes ou mesmo a possibilidade de ler e visualizar o objeto em diferentes tipos de dispositivos computacionais, tais como um celular ou computador de mesa. São também abertos e passíveis de reprogramação, permitindo com que esses objetos sejam reutilizados de diferentes maneiras, tais como a possibilidade de se usar uma imagem digital para construção de um vídeo ou uma tabela de um texto para a construção de uma apresentação digital para uma aula. Por fim, eles podem ser distribuídos e copiados infinitamente, possuindo a característica de serem amplamente passíveis de circularem em diferentes tipos de mídias e redes de comunicação, sem reduzirem ou diminuírem os recursos inicialmente gerados.

Ao analisar esses atributos, fica claro que um conjunto novo de práticas e formas de se pensar os objetos são necessárias, no caso específico dos objetos museológicos, para o exercício de suas possibilidades de extroversão, fruição, pesquisa, difusão, documentação, preservação e educação. Essas possibilidades, em certa medida, podem agora se valer da flexibilidade e da maleabilidade de manipulação simbólica dos objetos digitais, podendo ser enriquecidas a partir da reflexão sobre como utilizar essas camadas de informação anteriormente mencionadas, bem como da manipulação de seus atributos específicos. Vale evidenciar aqui que um importante recurso sócio técnico torna-se disponível para o exercício do fazer museal, precisando, para tal, ser incorporado e digerido pelo campo museológico a partir de suas questões. De certa maneira, esse olhar que aqui se propõe para o objeto digital pede ao campo museal para que ele também se flexibilize e se permita experimentar novas maneiras de relacionamento e socialização em rede. 
Uma vez colocadas as características dos objetos digitais, chega o momento em que se pode observar com mais precisão as práticas sociais percebidas como características da cultura digital e que podem ser aqui apropriadas para o contexto da educação museal. Em Autor (2018), são apontadas 4 formas de cultura que estão ligadas ao conceito de cultura digital. São elas, a cultura do hiperlink, a cultura da mensagem instantânea, a cultura da timeline e a cultura do algoritmo.

Na perspectiva da cultura do hiperlink, o que se observa é a constituição de uma prática social de conexão entre objetos digitais, na qual, por exemplo, as pessoas adquirem o hábito se comunicarem por meio de links, seja compartilhando artigos de revistas, jornais ou vídeos em suas redes sociais, seja produzindo textos em blogs que se referenciam a outros objetos digitais por meio de links. O processo de estabelecer um link é a prática que explicita essa ação de ligar objetos digitais, convidando pessoas a consumirem conexões específicas as quais são submetidas cotidianamente. Tome, por exemplo, o cotidiano de leitura de mensagens instantâneas por meio aplicativo WhatsApp de uma pessoa. Ela é submetida a uma intensa curadoria de links selecionados e compartilhados por meio de seus contatos pessoais e grupos dos quais faz parte. Além da curadoria dos objetos digitais, os mesmos, em geral, vêm acompanhado de informações contextuais que explicitam os motivos de compartilhamento e circulação desses objetos. Nesse sentido, os objetos digitais são manipulados, selecionados, compartilhados, contextualizados e constituem um verdadeiro acervo de conteúdos simbólicos que se tornaram presentes como referenciais culturais no cotidiano da sociedade.

Já a cultura da mensagem instantânea constitui a dinâmica temporal com a qual a comunicação contemporânea se dá. As mensagens chegam e podem, a depender da disponibilidade das pessoas, estabelecerem fluxos síncronos de comunicação, onde a interação se dá em tempo real. Não apenas a temporalidade desse processo é uma característica do digital, como também o tipo de objetos digitais que ela comporta. Por dentro das mensagens, conteúdos multimídia podem ser enviados, textos, áudio, vídeo, animação, entre tantos outros. As formas de sinalização das mensagens também aqui lhe são características. Seja por meio de sinais sonoros, vibração ou sinais visuais, as mensagens demandam atenção e pedem intervenção em seu fluxo de circulação.

A cultura da timeline constitui uma dinâmica que se pode observar pela forma como a informação e a comunicação é organizada. As mensagens chegam e se empilham umas sobre as outras, fazendo com que as primeiras que chegaram fiquem em posições distantes da atenção imediata do usuário, que para acessá-las terá de rodar a pilha para baixo em busca da sua presença. Essa é uma característica presente em praticamente qualquer aplicativo contemporâneo de mídia social. Ela produz o efeito de sempre priorizar o novo, o atual, o recém 


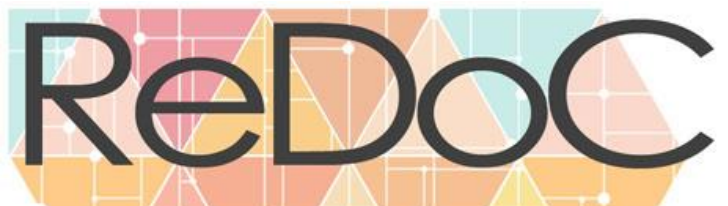

\section{Revista Docência e Cibercultura}

publicado, dificultando o acesso do mais antigo, daquilo que já foi exibido anteriormente. Essa prática produz efeitos extremamente importantes no modo de organização da comunicação contemporânea, pois ela evidencia a forma com que as pessoas serão levadas a visualizar e interagir com as informações que recebem. Outra característica importante derivada dessa prática é a dificuldade de busca e recuperação da informação. Encontrar conteúdos específicos que foram visualizados a tempos atrás pode ser complexo, difícil e, por muitas das vezes frustrantes. As tecnologias aqui envolvidas não priorizam essas funcionalidades, mas sim o consumo imediato da informação.

Por fim, temos a cultura do algoritmo. O algoritmo deve ser aqui entendido como os cálculos matemáticos e computacionais exercidos para selecionar e filtrar aquilo que será exibido aos diferentes usuários. O que está em jogo aqui são os critérios desses cálculos, ou seja, que elementos da experiência do usuário são levados em consideração para que se estabeleça, a muitas das vezes sem sua determinação explícita de interesse, os conteúdos aos quais será submetido. Os algoritmos atuais levam consideração vários atributos, tais como os conteúdos que um usuário mais curte, mais comenta, mais compartilha, mais visualiza, entre outros atributos, para com isso formar um certo perfil digital desse usuário e filtrar conteúdos de forma a lhe mostrar mais daquilo que ele mais gosta. De fato, essa prática evidencia uma enorme desigualdade social entre aqueles que podem criar algoritmos e definir suas formas de cálculo e aqueles que são submetidos a eles a partir das aplicações digitais que utilizam. Aqui, sem dúvida alguma, há implicações enormes para a discussão a respeito das questões culturais.

Por meio da análise dessas quatro práticas sociais aqui relatadas, abre-se a questão sobre como lidar com elas, não apenas no sentido de se adaptar a suas características, mas, sobretudo, a produzir intervenções e experiências singulares e específicas que possam usar de suas características para o exercício da educação museal. Para isso, como uma primeira e necessária etapa inicial, é fundamental que os museus possam refletir sobre quais objetos digitais, na concepção apresentada neste artigo, gostariam de disponibilizar aos seus usuários. Sem dúvida, uma primeira etapa poderia estar vinculada a abertura da documentação dos acervos musealizados, a digitalização dos objetos físicos, a constituição de repositórios digitais desses objetos bem como a produção de novas camadas de informação sobre eles, oferecendo contextos específicos com os quais o educativo do museu gostaria de apresentar esses objetos e permitir possíveis interações com os mesmos. A documentação, nesse sentido, deixa de ter um caráter mais voltado a gestão do acervo e passa a adquirir características de um objeto digital de aprendizagem e socialização desse mesmo acervo. Sem essa organização inicial e um plano específico para o museu refletir sobre que objetos digitais gostaria de possuir, o que espera fazer com eles e como eles podem ser utilizados para suas estratégias educacionais, outras práticas tornam-se quase inviáveis ou muito complexas de serem executadas. Os educadores, nesse sentido, podem e devem ter um papel importante na definição da organização 


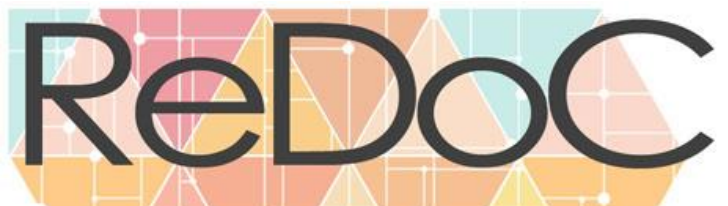

\section{Revista Docência e Cibercultura}

dessas informações, na medida em que são os responsáveis por parte importante das estratégias de socialização e apropriação pública dos conteúdos dos museus (AUTOR, 2015).

No entanto, uma vez o museu dispondo de objetos digitais organizados segundo suas prioridades e lógicas internas, outras possibilidades agora se tornam disponíveis. Dentro da lógica das quatro culturas acima mencionadas, o museu pode se abrir ao exercício de experiências que dialogam com tais práticas. Não se pretende aqui ser exaustivo em exemplos, pois de fato, as possibilidades de exercício de apropriação dessas práticas são infinitas e novas e surpreendentes possibilidades podem surgir a qualquer momento. No entanto, pode-se visualizar algumas formas possíveis aqui de serem explicitadas.

Uma vez os objetos digitais disponíveis para uso, poderia se pensar na possibilidade de experimentos e exercícios que permitissem às pessoas conectá-los, combiná-los e produzirem narrativas, por meio textuais ou gráficas, sobre os seus sentidos de apropriação dos mesmos. Trata-se de uma verdadeira bricolagem digital. Os resultados desses exercícios poderiam ser compartilhados, divulgados e difundidos ao gosto de seus criadores, evidenciando novas formas de valorização de sua própria produção. O exercício do link se manifesta como prática. Novos formatos de comunicação poderiam ser pensados entre os grupos educativos e seu público. Desde a criação de grupos de discussão em aplicativos já existentes de mensagem instantânea para difusão de objetos digitais em periodicidades a serem determinadas, realização de pesquisa de público ou conteúdos relacionados aos temas trabalhados pelo museu, até a criação novos aplicativos com vistas a produzirem lógicas comunicacionais próprias, as perspectivas da cultura da timeline e da mensagem instantânea poderiam ser aqui experimentadas e mesmo questionadas.

Por fim, e aqui vale frisar que um campo enorme de pesquisa e experimentação se abre, novos algoritmos e lógicas computacionais de curadoria e filtro de conteúdos relevantes poderiam ser experimentados como forma de oferecer objetos digitais relevantes a usuários que aderirem a esses serviços. Lógicas que priorizem interesses educacionais, a valorização da memória, as culturas tradicionais e a valorização de perspectivas culturais que se gostariam de evidenciar poderiam ser trabalhadas em lógicas computacionais diversas dos algoritmos atuais, permitindo novos exercícios de interação e distribuição dos objetos digitais.

\section{CONCLUSÃO}

A cultura digital e a educação museal se encontram como campos de enorme potencialidade para a experimentação de novas práticas sociais explicitadas na presente pesquisa. A cultura 


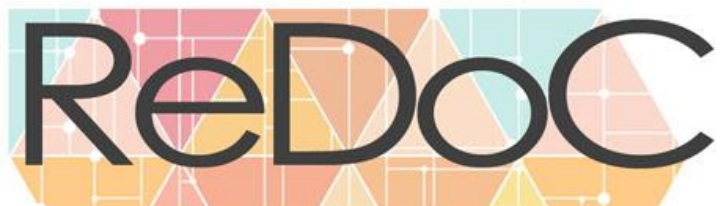

\section{Revista Docência e Cibercultura}

digital, com suas particularidades e especificidades técnicas, aporta perspectivas de apropriação dos objetos digitais em novas formas de socialização, abrindo espaço para uma inventividade a ser explorada a partir das características da flexibilidade e maleabilidade desses objetos. A educação museal, por sua vez, também apresenta um conjunto de especificidades e se encontra fortemente atrelada aos acervos musealizados e a reflexão que se propõe a criar caminhos e maneiras de facilitar sua apropriação a partir de práticas educacionais.

Tem-se, por um lado, a possibilidade de educar a partir dos acervos, por outro lado, a possibilidade de transformar esses acervos em objetos digitais e se valer de um conjunto novo de práticas sociais que têm por objetivo ampliar o potencial de socialização dos objetos. Essa perspectiva traz impactos para o próprio conceito de educação museal que, na esteira de uma visão ampliada de museu e de patrimônio, potencializada no bojo das discussões que trouxeram a ideia de museu integral para o campo da Museologia (Varine, 2010), pode ter uma nova compreensão de sua especificidade. Os usos apontados pelos novos dispositivos sócio técnicos digitais trazem para a equipe educativa de um museu local, a possibilidade de uma prática educacional que acontece em espaços não convencionais (na rede digital), em um tempo que não é o da visita ao edifício do museu, e ressignificando a ideia de objeto, e mesmo do que seja patrimônio intangível. Tempo, espaço e objeto, os já clássicos elementos apontados por Van Praët e Poucet (1992) como constituintes da "pedagogia museal", são alargados e transformados pelas possibilidades trazidas pela cultura digital. Apesar do aprofundamento dessa discussão não caber nos limites deste texto, aponta-se aqui a necessidade de refletir como os impactos da cultura digital no fazer educacional museal podem transformar o que se entende pela especificidade dessa tipologia educacional ${ }^{6}$.

Sabe-se, no entanto, que para o exercício de tal experimentação no campo da educação museal é preciso incorporar essas dimensões técnicas de produção, manipulação e gestão dos objetos digitais na formação do profissional museólogo, e do educador museal mais especificamente. É preciso que ele seja formado nos cursos de graduação, especialização e pós-graduação a compreender as novas dimensões informacionais da documentação museológica, tornando-a disponível para ser socializada em rede a partir de sua constituição como objetos digitais.

Para concluir, é importante ressaltar que essa reflexão aqui apresentada tem como pano de fundo a valorização social e ampliação do potencial de apropriação dos museus como instituições culturais no exercício de sua função. Compreende-se que a sociedade tem se transformado nas últimas décadas e a dimensão informacional das redes de comunicação

\footnotetext{
6 Para um aprofundamento das discussões sobre a especificidade da educação museal a partir dos elementos da pedagogia museal propostos por Van Praët e Poucet veja Martins (2011).
} 


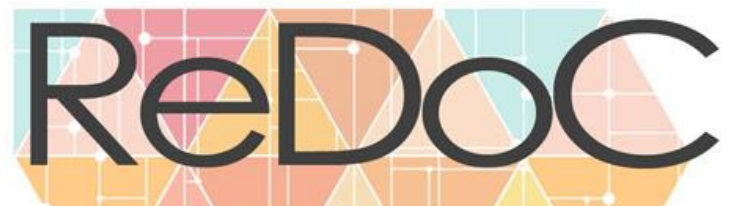

\section{Revista Docência e Cibercultura}

adquiriu enorme relevância nas práticas de socialização contemporâneas. A ideia de sociedade em rede se manifesta aqui como um determinante da conjuntura atual que precisa ser levado em consideração nessa reflexão. Não é mais possível, portanto, desconsiderar esse fenômeno como elemento necessário para se pensar o museu e sua função social, sobretudo aqui ressaltadas as características da educação museal em suas demandas por diálogo e interação com o público. É preciso, portanto, inventar os meios, criar as condições e propiciar caminhos para que essa apropriação se dê e para que novas experiências se desenvolvam alargando as dimensões conceituais e operatórias da própria museologia.

\section{REFERÊNCIAS}

AIDAR, Gabriela; AUTOR, 2018.

ALMEIDA, Adriana Mortara; STUDART, Denise Coelho; VALENTE, Maria Esther Alvrez . Pesquisa de Público em Museus: desenvolvimento e perspectivas. In: Guaracira; MARANDINO, Martha; LEAL, Maria Cristina. (Org.). Educação e Museu: A construção social do caráter educativo dos museus de ciências. 1ed.Rio de Janeiro: Access / FAPERJ, 2003, p. 129-157.

BARBIER, Frédéric. História das Bibliotecas: de Alexandria às Bibliotecas Virtuais. EdUSP. 2018. 396p.

BIZERRA, Alessandra Fernandes. Atividade de aprendizagem em museus de ciências. 2009. Tese (Doutorado) - Faculdade de Educação, Universidade de São Paulo, São Paulo, 2009.

BRUNO, Maria Cristina Oliveira (Coord.). O ICOM-Brasil e o pensamento museológico brasileiro: documentos selecionados. São Paulo: Pinacoteca do Estado, 2010.

BURKE, Peter. Uma história social do conhecimento II: da enciclopédia à Wikipedia. Editora Zahar. 2012. 414p.

CAZELLI, Sibele; MARANDINO, Martha; STUDART, Denise. (2003) Educação e Comunicação em Museus de Ciências: aspectos históricos, pesquisa e prática. In: GOUVÊA, Guaracira; MARANDINO, Martha; LEAL, Maria Cristina. (Org.). Educação e Museu: a construção social do caráter educativo dos museus de ciências. Editora Access/Faperj, Rio de Janeiro, p.83-106

HUI, Yuk. What is a Digital Object? MetaPhilosofhy. Special Issue: Philoweb: Toward a Philosophy of the Web. V.43, n.4, Jul, p.380-395, 2012 
IBRAM. Política Nacional de Educação Museal - PNEM. Brasília, DF, 2017.

JACOB, Christian. Prefácio. In: BARATIN, Marc; JACOB, Christian. O poder das bibliotecas: a memória dos livros no Ocidente. Ed. UFRJ. 2006. 351p.

KALLINIKOS, Jannis; AALTONEN, Aleksi; MARTON, Attila. A theory of digital objects. First Monday, v. 15, n. 6, 2010. Disponível em:

<http://firstmonday.org/htbin/cgiwrap/bin/ojs/index.php/fm/article/view/3033/2564>. Acesso em: 7 jul. 2019.

MARTINS, Luciana Conrado. A constituição da educação em museus: o funcionamento do dispositivo pedagógico museal por meio de um estudo comparativo entre museus de artes

plásticas, ciências humanas e ciência e tecnologia. 2011. Tese (Doutorado) - Faculdade de Educação, Universidade de São Paulo, São Paulo, 2011.

. Como é criado o discurso pedagógico dos museus? Fatores de influência e limites para a educação museal. Museologia \& Interdisciplinaridade. v. 1, no. 6, mar. /abr., 2015, p. 14-20.

Existe um currículo museal? As teorias curriculares na compreensão da educação em museus. ETD- Educação Temática Digital Campinas, São Paulo, v.20, n.3, p.640-661, 2018.

MARTINS, Dalton Lopes. As práticas da cultura digital. Revista do Centro de Pesquisa e Formação / No 7, novembro 2018.

NAVARRETE, Trilce; BOROWIECK, Karol J. Change in access after digitization: ethnographic collections in Wikipedia. ACEI Working paper series. Association for Cultural Economics International. Outubro 2015. Disponível online em:

<https://ideas.repec.org/p/cue/wpaper/awp-10-2015.html>. Acesso em 15/07/2019.

SANTOS, Maria Celia Teixeira Moura. Encontros museológicos. Reflexões sobre a museologia, a educação e o museu. Rio de Janeiro: MINC/IPHAN/DEMU, 2008.

ROBERTS, Lisa C. From knowledge to narrative: educators and the changing museum. Washington, London: Smithsonian Institution Press, 1997.

VAN-PRÄET, Michel; POUCET, B. Les musées, lieux de contre-éducation et de partenariat avec l'école. Éducation \& Pédagogies, n.16, 1992.

VARINE, Hugues de. As raízes do futuro. Editora Medianiz. 2013. 255p.

VESSURI, Hebe. Museos en la transición digital ¿Nuevas asimetrías?. In: Göbel, B. y Chicote, G. (Ed.). (2017). Transiciones inciertas: Archivos, conocimientos y transformación 


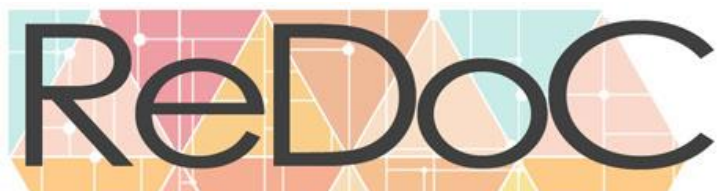

Revista Docência e Cibercultura

digital en América Latina. La Plata: Universidad Nacional de La Plata. Facultad de Humanidades y Ciencias de la Educación; Berlín: Ibero-Amerikanisches institut.

(Variaciones; 1). Disponível em:

<http://libros.fahce.unlp.edu.ar/index.php/libros/catalog/book/99>. Acesso em: dez. 2018. 